\title{
Celebration of Professor Wen-Jei Yang's 70th Birthday
}

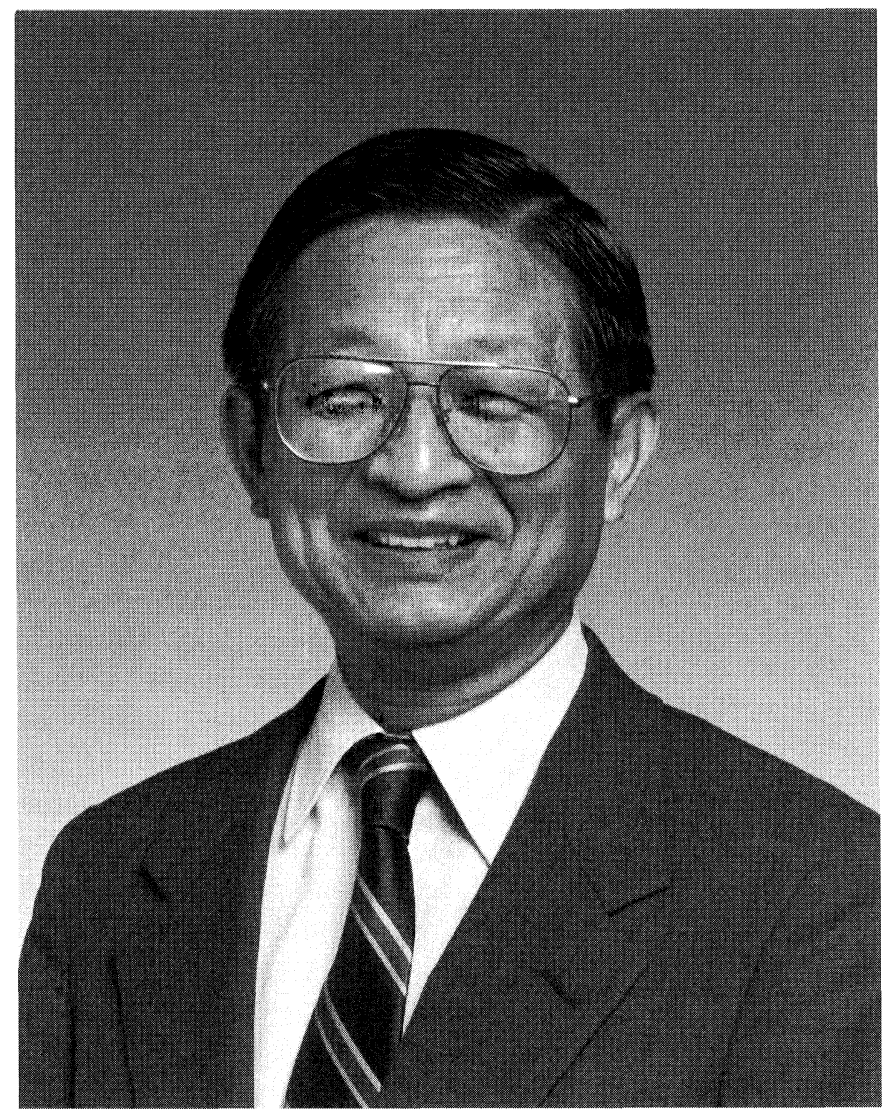

Professor Wen-Jei Yang celebrated his 70th birthday this year. He was born in Kaohsiung, Taiwan, on October 14, 1931. He received his B.S. degree in Mechanical Engineering in 1954 from the National Taiwan University in Taipei, Taiwan, an M.S. degree in Mechanical Engineering in 1956, and a Ph.D. degree in Mechanical Engineering in 1960 from the University of Michigan at Ann Arbor. After graduation, he worked at the University of Tokyo, the Institute of Industrial Science, and Mitsui Shipbuilding Company for one year in Japan. Since 1961, Dr. Yang has been a faculty member in the Mechanical Engineering Department at the University of Michigan, where he has conducted research and taught courses in thermodynamics, fluid mechanics, heat transfer, and biomechanics. His well-known reputation has attracted many scholars and students from around the world to conduct research under his guidance. Professor Yang has supervised $43 \mathrm{Ph} . \mathrm{D}$. students and 13 visiting research associates, and has hosted 52 visiting scholars and postdoctoral fellows. His students are now professors at leading institutions and in leadership positions in industry and government around the world. Professor Yang has conducted extensive research in heat transfer, fluid control, biomechanics, flow visualization, solar energy, compact heat exchangers, and flow and heat transfer in rotating machinery. He has earned a national and international reputation as a productive researcher in heat transfer, fluid flow, and bioengineering. His extensive research contributions have been published in nearly 700 technical papers and 10 books covering a wide range of heat transfer, fluid flow, and bioengineering fields. 
Professor Yang has contributed greatly to the technical conferences among the international community. He organized and co-chaired the US-Japan Heat Transfer Joint Seminar in Tokyo in 1980; the first US-Japan Thermal Engineering Conference held in Honolulu in 1983; and the US-Japan Heat Transfer Joint Seminar in San Diego in 1985. In particular, through his global vision, he coordinated and established the Pacific Center of Thermal-Fluids Engineering in 1985. The Center has served four series of international conferences: International Symposium on Transport Phenomena and Dynamics of Rotating Machinery, International Symposium on Transport Phenomena, Pacific Symposium on Flow Visualization and Image Processing, and International Conference on Mechanics in Medicine and Biology. The Center has initiated three journals: International Journal of Rotating Machinery, Journal of Flow Visualization and Image Processing, and International Journal of Transport Phenomena. Recently, he has established a new journal entitled Journal of Mechanics in Medicine and Biology and serves as the Editor-inChief.

Professor Yang has been very active in many technical societies. He is a member of the ASME; AIAA, American Association for the Advancement of Science; American Heart Association; Visualization Society of Japan; Michigan Academy of Science, Arts, and Letters; New York Academy of Sciences; International Flow Visualization Society; and the founding member of International Society for the Study of Mathematical Models in Medicine. Professor Yang has received numerous recognitions and awards, which include Fellowship Awards from Japan Society for the Promotion of Science $(1975,1983)$, Italian National Research Council (1986) and German Research Society (1988), Fellow of ASME (1983), Fellow of International Biographic Association (1984), ASME Heat Transfer Memorial Award (1984), JSME Thermal Engineering Memorial Award (1992), C. Strouhal Award in Flow Visualization of the International Flow Visualization Society in Prague (1989), Associate Fellow of AIAA (1989), T. Asanuma Award in Flow Visualization of the Visualization Society of Japan (1998), and Fellow of American Institute for Mechanical and Biological Engineering (2001).

We selected seven papers for this special issue of the International Journal of Rotating Machinery to celebrate Professor Yang's 70th birthday. We sincerely wish him and his family continued success, good health, and happy life.

\section{Je-Chin Han} Sadanari Mochizuki Robert Hendricks Tsutomu Adachi Yoshinobu Tsujimoto Chi-Yeou Soong Tien-Chien Jen 

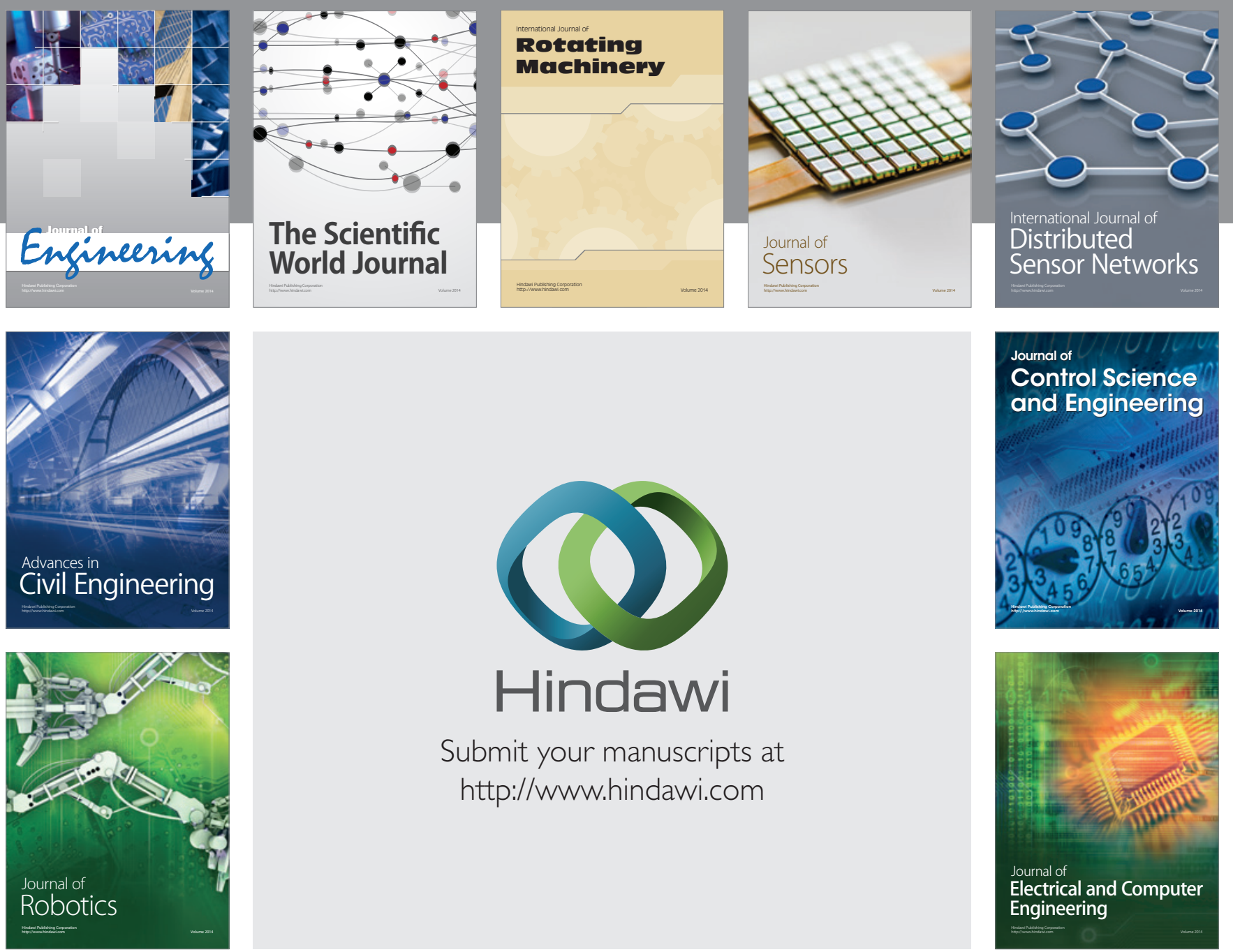

Submit your manuscripts at

http://www.hindawi.com
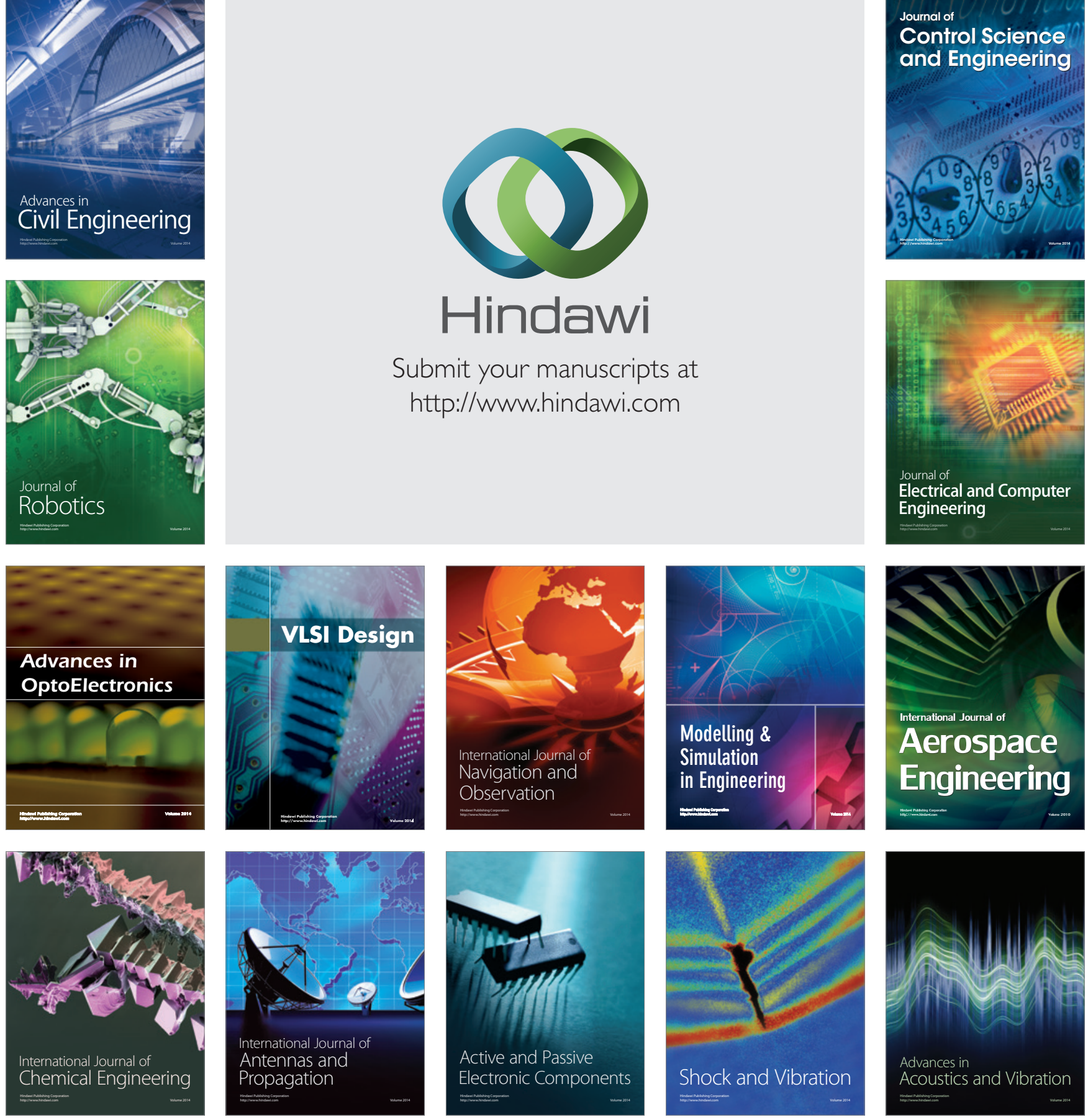